\title{
Preventing diseases in round-the-world travelers: a contemporary challenge for travel medicine advice
}

\author{
Karis Maria de Pinho Rodrigues ${ }^{[1]}$ and Beatriz Meurer Moreira ${ }^{[2]}$ \\ [1]. Departamento de Medicina Preventiva, Centro de Informação em Saúde para Viajantes (Cives), \\ Faculdade de Medicina, Universidade Federal do Rio de Janeiro, Rio de Janeiro, RJ, Brasil. \\ [2]. Instituto de Microbiologia Paulo de Goés, Universidade Federal do Rio de Janeiro, Rio de Janeiro, RJ, Brasil.
}

\begin{abstract}
Providing advice for travelers embarking on long-term trips poses a challenge in travel medicine. A long duration of risk exposure is associated with underuse of protective measures and poor adherence to chemoprophylaxis, increasing the chances of acquiring infections. Recently, in our clinic, we observed an increase in the number of travelers undertaking round-the-world trips. These individuals are typically aged around 32 years and quit their jobs to embark on one-to-two-year journeys. Their destinations include countries in two or more continents, invariably Southeast Asia and Indonesia, and mostly involve land travel and visiting rural areas. Such trips involve flexible plans, increasing the challenge, especially with regard to malaria prophylaxis. Advising round-the-world travelers is time-consuming because of the amount of information that must be provided to the traveler. Advisors must develop strategies to commit the traveler to his/her own health, and verify their learnings on disease-prevention measures. Contacting the advisor after the appointment or during the trip can be helpful to clarify unclear instructions or diagnosis made and prescriptions given abroad. Infectious diseases are among the most frequent problems affecting travelers, many of which are preventable by vaccines, medicines, and precautionary measures. The dissemination of counterfeit medicines, particularly antibiotics and antimalarial medicines, emphasizes the need for travelers to carry medicines that they may possibly need on their trip. Additional advice on altitude, scuba diving, and other possible risks may also be given. Considering the difficulties in advising this group, we present a review of the main recommendations on advising these travelers.
\end{abstract}

Keywords: Round-the-world travelers. Long-term travelers. Infectious diseases. Malaria prophylaxis. Vaccines.

\section{INTRODUCTION}

In recent years, we have observed a marked increase in the number of travelers embarking on long-term journeys around the world. These travelers are quite different from the young, adventurous backpackers. Among 36 such travelers who attended a travel clinic in Rio de Janeiro, Brazil, the mean age was 32 years, and the length of stay abroad was approximately $1.1 \mathrm{y}$. These young adults quit their jobs to spend long time abroad, with their destinations invariably including Southeast Asia and Indonesia. Table 1 presents a list of places visited by the 36 travelers who attended our clinic.

These travelers do not fit into the most-studied categories of long-term travelers, such as peace corps volunteers ${ }^{1}$, expatriates ${ }^{2,3}$, or those visiting friends and relatives ${ }^{4,5}$. Nonetheless, they are at risk for a long period, with increased chances of underuse of personal protective measures and poor adherence to continuous chemoprophylaxis, increasing the chances of contracting diseases ${ }^{6,7}$. The particular challenge they pose on advising is the

Corresponding author: $\mathrm{Dr}^{\mathrm{a}}$ Karis Maria de Pinho Rodrigues. e-mail: karis@cives.ufrj.br; karismpr@gmail.com

Received 10 December 2017

Accepted 27 March 2018 flexibility of travel plans; they just know the approximate period to spend in each country or continent, and crucial details for travel advice will possibly change along the trip. This uncertainty is particularly important concerning malaria chemoprophylaxis, as drug therapy must start from one day to two weeks before departure ${ }^{3}$.

Considering the difficulties in advising this group, we review and summarize the main recommendations for advising roundthe-world travelers (RWT).

\section{TIME SPENT DURING APPOINTMENT}

Travelers must understand the importance of following protective measures thoroughly. However, adherence to preventive strategies can be as low as $25 \%$, tending to decrease in the long term ${ }^{8-10}$ owing to lack of motivation, health beliefs, fear of side effects, or poor communication, resulting in limited understanding and forgetting the information provided ${ }^{11,12}$. Therefore, advisors' communication skills are critical. Advice should include an exhaustive discussion of the risks and protective measures, along with strategies to respond adequately to illness or injury that may occur during the trip, including sentinel symptoms suggesting serious infections, such as fever during or after visiting malaria-risk areas, profuse or bloody 
TABLE 1: Destinations visited by 36 round-the-world travelers who attended a travel clinic in Rio de Janeiro.

\begin{tabular}{lc}
\hline Destination & \multicolumn{1}{c}{ Travelers } \\
\cline { 2 - 2 } & $\mathbf{N}(\%)$ \\
\hline Southeast Asia & $33(92.0)$ \\
Indonesia & $27(75.0)$ \\
\hline Indian subcontinent & $26(72.0)$ \\
Africa & $25(69.0)$ \\
Europe & $24(67.0)$ \\
Asia (aside from India) & $22(61.0)$ \\
South America & $15(42.0)$ \\
Oceania & $12(33.0)$ \\
Middle East & $11(31.0)$ \\
North America & $10(28.0)$ \\
Central America & $8(22.0)$ \\
\hline
\end{tabular}

N: number; \%: percentage.

diarrhea, or fever associated with cutaneous lesions ${ }^{12}$. Advising RWT is time-consuming and frequently takes more than one meeting. During the first appointment, travel plans are still being built. Subsequent visits allow completing and reinforcing the advice, and verifying the extent of learning.

\section{INFORMATION AND COMMUNICATION TECHNOLOGY}

Communication between doctors and patients via telephone, internet, and video has already been accomplished decades ago. Information and communication technology (ICT) is an indispensable innovation for modern healthcare provision ${ }^{13}$, and such technology can certainly be beneficial to travelers and travel medicine advisors.

Instant messaging and e-mail allow travelers to keep in touch with clinicians, exchanging information about symptoms, healthcare facilities, and laboratory tests. Travelers often forget instructions received during consultation ${ }^{11}$, and contact with the advisor during the trip can help clarify uncertainties, improve compliance, and prevent improper use of medications. They usually seek advice when some health issue occurs to make sure they will make the best decision, such as sending a message after a dog bite or a cat scratch to make sure of the need to receive a rabies vaccination, or to confirm the commencement of malaria prophylaxis before moving to an area despite having received written information on the subject. Some ask for orientation to receive vaccines abroad after changes in travel plans. During consultation, travelers do not become skilled enough to deal with such specialized information. In our experience, a quick contact with the travel medicine doctor certainly helps the traveler to take the best decision. Nevertheless, travelers and physicians should be aware that online communication has limitations and can be disastrous if considered a substitute to face-to-face consultation ${ }^{14}$. Physicians' availability must be agreed up on previously and included in the consultation costs. However, because of the unpredictability of occurrence, it must be made clear that physicians may not be reachable timeously. Other helpful tools are smartphone applications to store medical information, such as health history, allergies, and regular medication.

\section{INFECTIOUS DISEASES}

Infectious diseases are among the most frequent problems, and many of them are preventable with vaccines, medicines, and precautionary measures ${ }^{15}$.

\section{vector-borne diseases}

Strategies to protect from vector-borne diseases must be reinforced, as compliance with use of barrier methods such as sleeping under bed-nets or using insect repellents can be as low as $19 \%{ }^{16}$, tending to decrease along the journey. Foldable net tents are more convenient and can improve compliance.

\section{Malaria}

Malaria is the most frequent cause of death from infections among travelers and is preventable with appropriate precautions ${ }^{17,18}$. To properly assess the actual chemoprophylaxis needed requires a significant amount of time to discuss travel plans and map malaria risk areas. Travelers must learn to adapt the prescription if routes change and program chemoprophylaxis before reaching risk areas.

When choosing appropriate malaria prophylaxis for RWT, advisors must deal with the lack of consensus between different guidelines, and the differences in the chemoprophylactic 
regimens licensed and available in different countries. RWT usually travel by land and spend lengthy time in rural areas, increasing the risk of illness in regions with precarious health systems, justifying chemoprophylaxis in places where, according to many guidelines, for short-term trips it would not be advisable, such as the Indian subcontinent and many parts of South-East Asia and Indonesia.

Doxycycline or atovaquone-proguanil are convenient drugs, as they can be started one to two days before entering a risk area, unlike mefloquine, which must be started two weeks ahead. Additionally, mefloquine resistance is reported in areas frequently explored by land or boat, such as the borders of Thailand, Myanmar, Cambodia, China, Laos, and Vietnam ${ }^{19}$.

Additional care includes carrying extra prophylactic pills in case of unplanned visits to malaria-endemic regions and carrying one/two sets of malaria treatment pills in case malaria is suspected or confirmed. Purchasing medicines in Sub-Saharan Africa or Asian countries is not advisable because drugs may be counterfeit, as reported for more than $50 \%$ of artemisinin products in those areas ${ }^{20,21}$.

Travelers are frequently concerned about using malaria prophylaxis for a long time and advisors must discuss pros and cons of each choice, based on clinical conditions, resistance patterns, travel style and budget. There is little evidence of harm in long-term use of drugs for malaria chemoprophylaxis tolerated in the short term. All regimens may be used longer when justified by malaria risk ${ }^{6,22}$. The inaccuracy of the data on endemicity in different risk areas, lack of information about incidence of diseases in travelers, and the many different travel styles make it impossible to determine precisely the risk of getting infected in each place. Standby emergency treatment (SBET) is recommended in some countries (e.g., Switzerland, Germany, and Austria) for travelers visiting areas where the risk of malaria is considered lower than the risk of serious adverse drug reactions from use of chemoprophylaxis ${ }^{23}$. SBET is the self-administration of antimalarial drugs when the disease is suspected and medical attention is unavailable within $24 \mathrm{~h}$ of symptoms onset. It is indicated only in emergency situations, as a life-saving measure. After taking the medication, the traveler must seek medical attention at the first opportunity to exclude other serious causes of fever. Travelers should also be warned that a minimal period of 6 days should have elapsed after entering the malaria-endemic area to cogitate treatment ${ }^{23}$. Considering the uncertainty in travel plans, SBET could be a convenient option. However, RWT generally mix high- with low-risk areas, with unreliable diagnosis available, making SBET unsuitable. This strategy must be discussed with travelers reluctant to take chemoprophylaxis, who are prone to nonadherence, and who presented serious adverse events before. However, considering both the risk of buying counterfeit drugs and the long stay in areas with precarious health systems, this strategy should be recommended for RWT not as an alternative, but in addition to chemoprophylaxis.

The use of rapid diagnostic tests for malaria for self-diagnosis by travelers is considered inaccurate, as sick individuals have difficulty with following procedures and interpreting results ${ }^{24,25}$.

\section{Yellow fever}

RWT may visit yellow fever risk areas, or invariably places without risk but with a vaccine requirement, such as Asia and Indonesia. Since June 2016, the World Health Organization (WHO) removed the 10-year booster recommendation from the International Health Regulations ${ }^{26}$. Occurrence of epidemics, such as those in Angola and Brazil recently, can change requirements. Therefore, the status of each country in the travel-plan should be reviewed, as even transit may fall under requirement. In this case, a vaccine may be offered upon entry, or travelers may be detained for up to six days to ensure that they are not infected ${ }^{27}$.

\section{Japanese encephalitis}

Japanese encephalitis (JE) is caused by a Flavivirus and is transmitted to humans through bites from infected mosquitoes of the Culex species. It is the most common vaccine-preventable cause of encephalitis in Asia, with only $1 \%$ developing clinical disease. The estimated risk for travelers is considered very low $(<1$ per million people traveling from non-endemic countries to Asia). Cases among travelers are correlated with long stay ( $\geq 1$ month), rural area visits, and spending time under very basic conditions; thus, immunization for JE is generally recommended ${ }^{28-30}$. There are four vaccines available for JE. The inactivated Vero-cell derived vaccines require multiple doses. The vaccine derived from the Beijing- 1 strain, available in Japan, requires 28 days for complete immunization with three doses. Ixiaro ${ }^{\circledR}$, available in US and Europe, requires 2 doses, with an interval of 28 days, which can be decreased to 7 days. The two live vaccines, SA 14-14-2 strain, available in China, and the chimeric, with yellow fever 17D as backbone, available in Australia and Thailand, require just one dose. JE vaccine is unavailable in many countries; therefore, when recommended, a traveler should select a route through a place where the vaccine is available before entering the risk area ${ }^{28,31}$. RWT visiting countries in Europe, Oceania, or the United States, Thailand, Singapore and China can receive the vaccine there. Travelers must be encouraged to visit a travel clinic and receive vaccination before their journey to the risk-prone area. Travel advisors must provide a letter prescribing the vaccine and justifying its recommendation.

\section{Other arbovirus: dengue, chikungunya and Zika}

Dengue, Zika and chikungunya are arboviruses transmitted by Aedes aegypti and Aedes albopictus mosquitoes, which are common in tropical and subtropical areas but present in all continents.

Dengue is the most common arboviral disease in the world. Four dengue virus (DENV) are known to cause human infection: DENV-1, DENV-2, DENV-3, and DENV-4. Reports of travelassociated dengue infection have been increasing. However, the actual rate of seroconversion is difficult to estimate due to cross reactivity among other arboviruses, including yellow fever, $\mathrm{JE}$ and $\mathrm{Zika}^{32}$. Zika virus infection, since its first description in humans in Nigeria in $1954^{33}$, had been considered a mild febrile illness characterized by maculo-papular rash, arthralgia, 
and conjunctivitis. However, in 2015, during the spread of the disease in Brazil, Zika infection was found to be associated with neurological complications. In pregnant women, the disease can cause fetal brain damage and microcephaly, whereas in adults it causes Guillain-Barré syndrome. Zika virus was also found in semen, and sexual transmission has been reported ${ }^{34}$. The attack rate is estimated at 14.6/1,000 inhabitants during epidemics; however, the exact risk for travelers remains unknown ${ }^{35}$.

Chikungunya virus originated in Africa, and was possibly introduced into Asia, Europe and the Americas by air travelers ${ }^{36}$. Chikungunya virus causes an acute febrile illness characterized by intense asthenia, myalgia, headache, rash, and typically accompanied by intense arthralgia. Chikungunya is rarely fatal ${ }^{36}$; however, it is associated with chronic arthralgia, leading to persistent incapacitation, requiring long-term treatment ${ }^{37}$. Risk to travelers is high in areas with epidemics ${ }^{36}$.

Currently, the singular protective measure available against these diseases is to avoid mosquito bites. Travelers to endemic risk areas should be encouraged to adhere to barrier methods (bed nets) and use reliable repellents (those containing N,Ndietil-meta-toluamida (DEET) $20-50 \%$, picaridin $20 \%$ or para-Menthane-3,8-diol (PMD) 30\% ${ }^{38}$. The licensed dengue vaccine is unsuitable for travelers owing to limited efficacy and a prolonged schedule ${ }^{39}$. Visitors to areas with active Zika transmission should be warned about mosquito-borne and sexual transmission routes and Zika congenital syndrome. People must be advised to adopt safe-sex practices, and women to postpone pregnancy for up to six months after return ${ }^{40}$.

\section{FOOD AND WATER-BORNE DISEASES}

RWT routes often include remote locations in low-income countries with poor sanitary conditions, increasing the risk of food and water-borne diseases.

\section{Vaccines for food and water-borne diseases}

Hepatitis A vaccine should be offered to susceptible RWT considering its favorable safety profile, immunogenicity, and high susceptibility of exposed individuals ${ }^{18}$. Typhoid fever vaccines, despite suboptimal efficacy ( $60 \%$ to $70 \%)$, should be strongly considered because of the long-term exposure in high risk areas, some of which can harbor resistant strains ${ }^{41}$. Wild poliomyelitis disease is currently exported only by Pakistan and Afghanistan; nevertheless, wild virus and circulating vaccinederived polioviruses are still present in Nigeria, Guinea, Lao People's Democratic Republic, Madagascar and Myanmar, justifying a booster dose of inactivated poliovirus vaccine if a primary polio vaccination has been administered more than 10 years before; and a complete vaccine series for unvaccinated individuals ${ }^{42,43}$. A booster polio vaccine dose is advisable even if travel plans exclude those countries, but extend to neighboring places where the virus can reemerge during the long trip. Cholera vaccines are rarely prescribed for travelers, except during outbreaks, due to their short-term protection. However, the disease remains endemic in countries of Africa, Southeast Asia as well as Haiti. Outbreaks emerged unpredictably ${ }^{44}$, as in Tanzania in $2016^{45}$ and Haiti in 2010 after an earthquake ${ }^{46}$.
Depending on the RWT activity plans, such as engaging in aid work, one of the following oral cholera vaccines should be considered: Dukoral ${ }^{\circledR}$ and ShanChol ${ }^{\circledR}$ (inactivated) or Vaxchora ${ }^{\circledR}$ (live) ${ }^{47}$. Dukoral ${ }^{\circledR}$ may produce some cross protection against enterotoxigenic Escherichia coli diarrhea. However, additional evidence is required to support the recommendation for its use for this indication ${ }^{48-50}$.

Additionally, food and water safety precautions must be followed because of the limited efficacy of some vaccines and against other agents transmitted by the oral route, such as bacteria and viruses causing diarrhea, hepatitis E, worms, and protozoa.

\section{Travelers diarrhea}

Traveler's diarrhea (TD) is one of the most common health problems for visitors to poor sanitary areas. Advisors must consider the consequences of $\mathrm{TD}$, in addition to the growing antibiotic resistance associated with $\mathrm{TD}^{51,52}$, particularly in those treated with antimicrobials ${ }^{53,54}$. For that reason, antimicrobials should be restricted to severe disease (incapacitating or bloody diarrhea). RWT must be instructed to recognize symptoms of severe diarrhea and to carry antimicrobials for self-administration. Azithromycin is currently the preferred antibiotic because of the widespread resistance to quinolones, particularly in Southeast and South Asia and especially related to Campylobacter spp. Quinolones and rifaximin are considered alternatives in some guidelines, but must be avoided in dysenteric diarrhea. Loperamide can be used as combined therapy. If symptoms do not improve in 24-36h, patients must seek medical attention ${ }^{55}$. Those presenting with mild ${ }^{55}$ to moderate symptoms of secretory diarrhea should be advised that those are self-limited and may improve with loperamide and $/$ or $^{56}$ racecadotril ${ }^{57}$.

Travelers must learn that oral rehydration and salt intake are essential, and carry rehydration packages or learn to produce an oral rehydration fluid with salt and sugar.

\section{AIR BORNE TRANSMITTED DISEASES}

\section{Measles, chickenpox, pertussis, and mumps}

The recent widespread increase in the incidence of measles, mumps, and pertussis underscores the need for RWT to be upto-date with routine immunization to protect themselves and the people at their destination ${ }^{58}$.

\section{Meningococcal meningitis}

Neisseria meningitidis serogroups A, B, C, Y, X and W135 cause meningococcal disease ${ }^{59,60}$. Even though the risk of acquiring disease for travelers is considered $l_{0}{ }^{61}$, it is a devastating disease. The disease course is often fulminant, which makes the prognosis worse in travelers to remote areas with limited or delayed access to qualified medical care ${ }^{62}$. The vaccines currently available are monovalent group A or C, several tetravalent presentations for groups A, C, W135 and $\mathrm{Y}$ (MCV4), and two monovalent group B vaccines. The MCV4 vaccines are required for Hajj/Umrah pilgrims as a visa prerequisite. For those going to the African meningitis 
belt and areas around Rift Valley and Great Lakes, MCV4 vaccine is recommended because of the increased disease prevalence ${ }^{59,63}$. RWT planning to be in close contact with local populations, including activities in schools or hospitals, or living under crowded conditions, should consider vaccination ${ }^{61,64,65}$. Those with underlying conditions, such as asplenia or other immune deficiencies related to immunoglobulin or complement deficiency, should also be vaccinated because of the increased risk of invasive disease ${ }^{61}$.

\section{Influenza and other respiratory infections}

Influenza vaccine can be recommended; however, efficacy may be limited considering the varied viruses circulating across hemispheres. Advice includes avoiding crowded, enclosed spaces, close contact with individuals with respiratory infections, and washing hands frequently ${ }^{66}$. Travelers going to avian flu risk areas in Asia or Southeast Asia should avoid exposure to wild birds and poultry ${ }^{67,68}$. During trips to the Arabian Peninsula, travelers must avoid contact with camels and their products, such as raw milk, urine or undercooked meat because of the Middle East respiratory syndrome coronavirus $^{69}$.

\section{DISEASES CAUSED BY ANIMAL AND ENVIRONMENTAL EXPOSURE}

\section{Rabies}

RWT itineraries frequently include high-risk rabies transmission areas, such as the Indian subcontinent, South East Asia, North Africa, Indonesia ${ }^{70}$, and Sub-Saharan Africa ${ }^{71}$. Immediate access to appropriate medical care is usually limited, and availability of rabies vaccine and rabies immunoglobulin (RIG) is uncertain or products are ineffective ${ }^{72}$. In some countries, such as Brazil, equine RIG (ERIG), or purified fractions of ERIG, may be available ${ }^{73}$; however, they may be less effective, have a shorter half-life and carry the risk of serum sickness ${ }^{74}$. Most injured travelers in those countries $^{70}$ will need to access a neighboring place or their home country to start or continue proper $\mathrm{care}^{74}$. Therefore, rabies pre-exposure prophylaxis is strongly recommended.

\section{Schistosomiasis and leptospirosis}

These diseases affect people exposed to lake and river waters. RWT frequently engage in activities in close contact with nature in wild and rural areas. Therefore, advice must include the risks of bathing in fresh water, mainly in areas wherein schistosomiasis is endemic. Considering the unpredictability of risk areas in some countries, screening of possibly exposed travelers on return must be considered ${ }^{75}$. Leptospirosis has a worldwide distribution, with a higher incidence in tropical climates, especially after flooding. Chemoprophylaxis is not generally prescribed; however, those taking doxycycline for malaria prevention will additionally be protected against leptospirosis. Awareness of leptospirosis risk factors will increase chances of early appropriate treatment for this potentially lethal disease ${ }^{76}$.

\section{SEXUALLY TRANSMITTED INFECTIONS}

Traveling has historically been an important risk factor for acquisition and spread of sexually transmitted infections (STIs). Over the last decades, $5-50 \%$ of short-term travelers engaged in casual sex during foreign trips, with a substantial risk of developing STIs ${ }^{77,78}$. RWT, even those with a partner, need advice about STIs, condom use, and hepatitis B vaccination, and to come for screening after return if they have engaged in casual sex during the trip ${ }^{78}$.

\section{MEDICINES TO CARRY}

According to the WHO, up to $10 \%$ of drugs available worldwide may be counterfeit; $78 \%$ of those are found in developing countries and $50 \%$ are antimicrobials ${ }^{79}$. Thus, RWT should carry medicines they may possibly needed along the trip, including antibiotics such as levofloxacin, azithromycin, and amoxicillin/clavulanic acid, for most respiratory, urinary tract, or intestinal bacterial infections. Medication should cover any preexisting medical conditions and general medications like pain and fever relievers, pre-packed rehydration salts, antacids, decongestants, antihistamines, motion sickness medication, and saline eye and nose drops ${ }^{80}$. Narcotic or psychotropic substances are subject to international laws, and lists with the amounts of those medicines allowed by each country must be checked before traveling ${ }^{81}$. Travelers must carry medicines in the original containers with clear labels, along with copies of all medical prescriptions in the language spoken at destination or, minimally, in English ${ }^{80}$.

\section{NON-INFECTIOUS RISKS}

RWT frequently engage in activities such as scuba diving, climbing and trekking at altitude which require alertness and fine motor coordination. Such activities can impact some infectious disease prophylactic decisions, such as prescription of mefloquine in those planning activities such as scuba diving or doxycycline for those planning heavy sun exposures ${ }^{18}$. These situations require a detailed discussion and more complex planning regarding malaria prophylaxis, sometimes requiring use of different drugs over the trip.

\section{CONCLUSIONS}

RWT are people embarking on long touristic adventures including risky places, with poorly predicted schedules at the time of consultation. Travel advice for RWT comprises an extensive range of travel medicine expertise. The challenges are: 1) to commit travelers to their own health; 2) to make individuals understand the risks and the importance of adopting preventive measures throughout the journey; 3 ) to decide the best options for malaria prophylaxis, preferably making notes in the travel plans about risk areas and right times to start and stop medication; 4) to discuss strategies for disease sentinel symptoms; 5) to prescribe medicines for potential illness, preexisting medical and general conditions; 6) to dedicate enough time to ensure most information is acknowledged; and, finally, 7) to deliver advice without undermining traveler's motivation for such a life experience. 


\section{Conflict of interest}

The authors declare that there is no conflict of interest

\section{REFERENCES}

1. Landman KZ, Tan KR, Arguin PM. Adherence to malaria prophylaxis among Peace Corps Volunteers in the Africa region, 2013. Travel Med Infect Dis. 2015;13(1):61-8.

2. Toovey S, Moerman F, van Gompel A. Special infectious disease risks of expatriates and long-term travelers in tropical countries. Part II: Infections other than malaria. J Travel Med. 2007;14(1): $50-60$.

3. Toovey S, Moerman F, van Gompel A. Special infectious disease risks of expatriates and long-term travelers in tropical countries. Part I: Malaria. J Travel Med. 2007;14(1):42-9.

4. Matteelli A, Carvalho ACC, Bigoni S. Visiting relatives and friends (VFR), pregnant, and other vulnerable travelers. Infect Dis Clin North Am. 2012;26(3):625-35.

5. Heywood AE, Forssman BL, Seale H, MacIntyre R, Zwar N. General practitioners' perception of risk for travelers visiting friends and relatives. J Travel Med. 2015;22(6):368-74.

6. Chen LH, Wilson ME, Schlagenhauf P. Prevention of malaria in long-term travelers. JAMA. 2006;296(18):2234-44.

7. Chen LH, Wilson ME, Davis X, Loutan L, Schwartz E, Keystone $\mathrm{J}$, et al. Illness in long-term travelers visiting geosentinel clinics. Emerg Infect Dis. 2009;15(11):1773-82.

8. Muller JM, Simonet AL, Binois R, Muggeo E, Bugnon P, Liet J, et al. The respect of recommendations provided in an international travelers' medical service: Far from the cup to the lips. J Travel Med. 2013;20(2):78-82.

9. Goldstein I, Grefat R, Ephros M, Rishpon S. Intent-to-adhere and adherence to malaria prevention recommendations in two travel clinics. J Travel Med. 2015;22(2):130-2.

10. Cunningham J, Horsley J, Patel D, Tunbridge A, Lalloo DG. Compliance with long-term malaria prophylaxis in British expatriates. Travel Med Infect Dis. 2014;12(4):341-8.

11. Bauer IL. Educational issues and concerns in travel health advice: Is all the effort a waste of time? J Travel Med. 2005;12(1):45-52.

12. Noble LM, Willcox A, Behrens RH. Travel clinic consultation and risk assessment. Infect Dis Clin North Am. 2012;26(3):575-93.

13. Jungwirth $D$, Haluza D. Information and communication technology and the future of healthcare: Results of a multi-scenario Delphy survey. Health Informatics J. 2017;1:1-13.

14. Sing A, Salzman J, Sing D. Problems and risks of unsolicited e-mails in patient-physician encounters in travel medicine settings. J Travel Med. 2001;8(3):109-12.

15. Behrens RH, Carroll B. Travel trends and patterns of travelassociated morbidity. Infect Dis Clin North Am. 2012;26(3):791802.

16. Sagui E, Resseguier N, Machault V, Ollivier L, Orlandi-Pradines E, Texier G, et al. Determinants of compliance with anti-vectorial protective measures among non-immune travellers during missions to tropical Africa. Malar J. 2011;10:232-40.

17. Muentener $P$, Schlagenhauf $P$, Steffen R. Imported malaria (1985-95): Trends and perspectives. Bull World Health Organ. 1999;77(7):560-6.

18. Shepherd SM, Shoff WH. Immunization in travel medicine. Prim Care. 2011;38(4):643-79.
19. Arguin PM, Tan KR. Malaria. In: Centers for Disease Control and Prevention. CDC Health Information for International Travel. New York, NY: Oxford University Press; 2016. p. 236-254.

20. Cockburn R, Newton PN, Agyarko EK, Akunyili D, White NJ. The global threat of counterfeit drugs: Why industry and governments must communicate the dangers. PLoS Med. 2005;2(4):e100.

21. Schlagenhauf P, Petersen E. Standby emergency treatment of malaria in travelers: Experience to date and new developments. Expert Rev Anti Infect Ther. 2012;10(5):537-46.

22. Chiodini PL, Field VK, Hill DR, Whitty CJM, Lalloo DG. Guidelines for malaria prevention in travelers from the United Kingdom. London: Public Health England; 2013. Updated 22 August 2013; [Internet]; acessed on: 08 September 2017. Available from: http:// webarchive.nationalarchives.gov.uk/20140714113755/http://www. hpa.org.uk/infections/topics_az/malaria/guidelines.htm

23. Genton B, D'Acremont V. Malaria prevention in travelers. Infect Dis Clin North Am. 2012;26(3):637-54.

24. Jelinek T, Grobusch M, Schwenke S, Steirl S, von Sonnenburg F, Nothdurft HD, et al. Sensitivity and specificity of dipstick tests for the rapid diagnosis of malaria in non-immune travelers. J Clin Microbiol. 1999;37(3): 721-3.

25. Jelinek T. Malaria self-testing by travellers: Opportunities and limitations. Travel Med Infect Dis. 2004;2(3-4):143-8.

26. Staples JE, Bocchini JA, Rubin L, Fischer M. Yellow fever vaccine booster doses: Recommendations of the advisory committee on immunization practices, 2015. Centers for Disease Control and Prevention (CDC). MMWR Morb Mortal Wkly Rep. 2015;64(23):647-50. June 19 $9^{\text {th }} 2015$. [Internet]; accessed on: 08 September 2017. Available from: https://www.cdc.gov/mmwr/ preview $/ \mathrm{mmwrhtml} / \mathrm{mm} 6423 \mathrm{a} 5 . \mathrm{htm}$ ?s_cid=mm6423a5_w.

27. World Health Organization (WHO). Country list. Yellow fever vaccination requirements and recommendations; malaria situation; and other vaccination requirements, 2016. 32p. [Internet]; accessed on: 08 September 2016. Available from: http://www.who.int/ith/ ITH_country_list.pdf.

28. Chen HL, Chang JK, Tang RB. Current recommendations for the Japanese encephalitis vaccine. J Chin Med Assoc. 2015;78(5):271-5.

29. Pavli A, Maltezou HC. Travel-acquired Japanese encephalitis and vaccination considerations. J Infect Dev Ctries. 2015;9(9):917-24.

30. Hills SL, Rabe IB, Fischer M. Japanese Encephalitis. In: Centers for Disease Control and Prevention. CDC Yellow Book 2016; Health Information for International Travel. New York, NY: Oxford University Press; 2016. p. 218-27.

31. World Health Organization (WHO). International Travel and Health. Vaccines. Japanese encephalitis. 2016. [Internet]; accessed on: 08 September 2016. Available from: http://www.who.int/ith/vaccines/ japanese_encephalitis/en/

32. Olivero RM, Hamer DH, MacLeod WB, Benoit CM, SanchezVegas C, Jentes ES, et al. Dengue virus seroconversion in travelers to dengue-endemic areas. Am J Trop Med Hyg. 2016;95(5):1130-6.

33. Macnamara FN. Zika virus: a report on three cases of human infection during an epidemic of jaundice in nigeria. Trans $\mathrm{R}$ Soc Trop Med Hyg 1954;48(2):139-45.

34. Tang BL. Zika virus as a causative agent for primary microencephaly: The evidence so far. Arch Microbiol. 2016;198(7):595-601.

35. Duffy MR, Chen T-H, Hancock WT, Powers AM, Kool JL, Lanciotti RS, et al. Zika virus outbreak on Yap Island, Federated States of Micronesia. N Engl J Med. 2009; 360:2536-43.

36. Weaver SC, Lecuit M. Chikungunya virus and the global spread of a mosquito-borne disease. N Engl J Med. 2015;372(13):1231-9. 
37. Ganu MA, Ganu AS. Post-chikungunya chronic arthritis--our experience with DMARDS over two year follow up. J Assoc Physicians India. 2011;59:83-6.

38. Alpern JD, Dunlop SJ, Dolan BJ, Stauffer WM, Boulware DR. Personal protection measures against mosquitoes, ticks, and other arthropods. Med Clin North Am. 2016;100(2):303-16.

39. Lim SK, Lee YS, Namkung S, Lim JK, Yoon IK. Prospects for dengue vaccines for travelers. Clin Exp Vaccine Res. 2016;5(2): 89-100.

40. World Health Organization (WHO). Prevention of sexual transmission of Zika virus. 2016. [Internet]; accessed on: 18 October 2016. Available from: http://www.who.int/csr/resources/ publications/zika/sexual-transmission-prevention/en/

41. Martin LB. Vaccines for typhoid fever and other salmonelloses. Curr Opin Infect Dis. 2012;25(5):489-99.

42. Gautret P, Wilder-Smith A. Vaccination against tetanus, diphtheria, pertussis and poliomyelitis in adult travellers. Travel Med Infect Dis. 2010;8(3):155-60.

43. The Green Book. Information for public health professionals on immunization. Immunization against infectious disease: poliomyelitis. 2013. p. 313-328. [Internet]; accessed 18 October 2016. [Updated 19 April 2013] Available from: https://www.gov.uk/ government/uploads/system/uploads/attachment data/file/148141/ Green-Book-Chapter-26-Polio-updated-18-January-2013.pdf

44. World Health Organization (WHO). Cholera cases report by year and by continent. 2016. [Internet]; accessed on: 18 October 2016. Available from: http://www.who.int/gho/epidemic_diseases/ cholera.

45. World Health Organization (WHO). Cholera United Republic of Tanzania. 2016. [Internet]; accessed on: 18 October 2016. Available from: http://www.who.int/csr/don/22-april-2016-cholera-tanzania/ en/.

46. Pan American Health Organization (PAHO). Epidemiological Update. Cholera. 2016. [Internet]; accessed on: 18 October 2016. Available from: http://www.paho.org/hq/index.php?option=com docman\&task=doc_view\&gid=35445+\&Itemid=999999\&lang=en.

47. Holmgren J, Svennerholm AM. Vaccines against mucosal infections. Curr Opin Immunol. 2012;24(3):343-53.

48. Jelinek T, Kollaritsch $H$. Vaccination with dukoral against travelers' diarrhea (ETEC) and cholera. Expert Rev Vaccines. 2008;7(5):561-7.

49. Ahmed T, Bhuiyan TR, Zaman K, Sinclair D, Qadri F. Vaccines for preventing enterotoxigenic Escherichia coli (ETEC) diarrhoea. Cochrane Database Syst Rev 2013(7):CD009029.

50. O'Ryan M, Vidal R, delCanto F, Carlos Salazar J, Montero D. Vaccines for viral and bacterial pathogens causing acute gastroenteritis: Part II: Vaccines for Shigella, Salmonella, enterotoxigenic E. coli (ETEC) enterohemorragic E. coli (EHEC) and Campylobacter jejuni. Hum Vaccin Immunother. 2015;11(3):601-19.

51. Arcilla MS, van Hattem JM, Haverkate MR, Bootsma MCJ, van Genderen PJJ, Goorhuis A, et al. Import and spread of extendedspectrum beta-lactamase-producing Enterobacteriaceae by international travellers (COMBAT study): a prospective, multicentre cohort study. Lancet Infect Dis. 2017;17(1):78-85.

52. Armand-Lefevre L, Ruppe E, Andremont A. ESBL-producing Enterobacteriaceae in travellers: doctors beware. Lancet Infect Dis. 2017;17(1):8-9.

53. Kantele A, Mero S, Kirveskari J, Lääveri T. Increased Risk for ESBL-Producing Bacteria from Co-administration of Loperamide and Antimicrobial Drugs for Travelers' Diarrhea. Emerg Infect Dis. 2016;22(1):117-20.
54. Kantele A, Mero S, Kirveskari J, Lääveri T. Fluoroquinolone antibiotic users select fluoroquinolone-resistant ESBL-producing Enterobacteriaceae (ESBL-PE) - Data of a prospective traveller study. Travel Med Infect Dis. 2017;16:23-30.

55. Riddle MS, Connor BA, Beeching NJ, DuPont HL, Kozanrsky P, Libman M, et al. Guidelines for the prevention and treatment of travelers' diarrhea: a graded expert panel report. J Travel Med. 2017; 24(Suppl 1):S57-S74.

56. Lääveri T, Sterne J, Rombo L, Kantele A. Systematic review of loperamide: No proof of antibiotics being superior to loperamide in the treatment of mild/moderate travellers' diarrhoea. Travel Med Infect Dis. 2016;14(4):299-312.

57. Jelinek T, Nothdurft HD, Haditsch M, Weinke T. Consensus paper treatment of acute traveler's diarrhea. Practice recommendation for travel advice. MMW Fortschr Med. 2017;159(Suppl 4):4-11.

58. Herman JS, Hill DR. Advising the traveller. Medicine. 2014;42:10711.

59. Harrison LH, Trotter CL, Ramsay ME. Global Epidemiology of meningococcal disease. Vaccine. 2009;27(Suppl 2):B51-63.

60. Halperin SA, Bettinger JA, Greenwood B, Harrison L, Jelfs J, Ladhani SN, et al. The changing and dynamic epidemiology of meningococcal disease. Vaccine. 2012;30(Suppl 2):B26-36.

61. Memish ZA, Goubeaud A, Bröker M, Malerczyk C, Shibl AM. Invasive meningococcal disease and travel. J Infect Public Health. 2010;3(4):143-51.

62. Wilder-Smith A. Meningococcal disease in travelers: a rare but devastating disease. J Travel Med. 2010;17(Suppl):1-2.

63. Mutonga DM, Pimentel G, Muindi J, Nzioka J, Klena JD, Morcos M, et al. Epidemiology and risk factors for serogroup X meningococcal meningitis during an outbreak in western Kenya, 2005-2006. Am J Trop Med Hyg. 2009;80(4):619-24.

64. Steffen R. The risk of meningococcal disease in travelers and current recommendations for prevention. J Travel Med. 2010;17(Suppl):9-17.

65. Cramer JP, Wilder-Smith A. Meningococcal disease in travelers: Update on vaccine options. Curr Opin Infect Dis. 2012;25(5):507-17.

66. Aiello AE, Coulborn RM, Aragon TJ, Baker MG, Burrus BB, Cowling BJ, et al. Research findings from nonpharmaceutical intervention studies for pandemic influenza and current gaps in the research. Am J Infect Control. 2010; 38(4):251-8.

67. Centers for Disease Control and Prevention (CDC). Influenza (Flu). Avian Influenza A (H7N9) virus. [Internet]. Updated Feb 2014; accessed on: 18 October 2016. Available from: http://www.cdc.gov/ flu/avianflu/h7n9-virus.htm.

68. Centers for Disease Control and Prevention (CDC). Highly Pathogenic Asian Avian Influenza A (H5N1) virus. [Internet]; Updated Oct 2015; accessed on: 18 October 2016. Available from: http://www.cdc.gov/flu/avianflu/h5n1-virus.htm.

69. Centers for Disease Control and Prevention (CDC). Midle East Respiratory Syndrome (MERS). [Internet]; Updated July 2016; accessed on: 18 October 2016. Available from: https://www.cdc.gov/ coronavirus/mers/about/index.html.

70. Gautret P, Parola P. Rabies vaccination for international travelers. Vaccine. 2012;30(2):126-33.

71. Schneider MC, Aguilera XP, Barbosa da Silva Junior J, Ault SK, Najera P, Martinez J, et al. Elimination of neglected diseases in Latin America and the Caribbean: a mapping of selected diseases. PLoS Negl Trop Dis. 2011;5(2):e964.

72. Uwanyiligira M, Landry P, Genton B, de Valliere S. Rabies postexposure prophylaxis in routine practice in view of the 
new centers for disease control and prevention and world health organization recommendations. Clin Infect Dis. 2012;55(2):201-5.

73. Hanlon CA, Shlim DR. Rabies. In: Centers for Disease Control and Prevention. CDC Yellow Book 2016; Health Information for International Travel. New York, NY: Oxford University Press; 2016. p 282-292.

74. Jentes ES, Blanton JD, Johnson KJ, Petersen BW, Lamias MJ, Robertson K, et al. The global availability of rabies immune globulin and rabies vaccine in clinics providing indirect care to travelers. J Travel Med. 2014;21(1):62-6.

75. Nicolls DJ, Weld LH, Schwartz E, Reed C, von Sonnenburg F, Freedman DO, et al. Characteristics of schistosomiasis in travelers reported to the geosentinel surveillance network 1997-2008. Am J Trop Med Hyg. 2008;79(5):729-34.

76. Matono T, Kutsuna S, Koizumi N, Fujiya Y, Takeshita N, Hayakawa K, et al. Imported Flood-Related Leptospirosis from Palau: Awareness of Risk Factors Leads to Early Treatment. J Travel Med. 2014;22(6):422-4.
77. Matteelli A, Carosi G. Sexually transmitted diseases in travelers. Clin Infect Dis. 2001;32(7):1063-7.

78. Korzeniewski K, Juszczak D. Travel-related sexually transmitted infections. International maritime health. 2015;66(4):238-46.

79. Kelesidis T, Falagas ME. Substandard/counterfeit antimicrobial drugs. Clin Microbiol Rev. 2015;28(2):443-64.

80. Lee AW. Travel health kits. In: Centers for Disease Control and Prevention. CDC Yellow Book 2016; Health Information for International Travel. New York, NY: Oxford University Press; 2016. p 138-141.

81. United Nations Office on Drugs and Crime (UNODC). Guidelines for national regulations concerning travelers under treatment with internationally controlled drugs. New York: UNODC; 2003. [Internet], 2013; accessed on 18 October 2016. Available from: http://www.incb.org/documents/Psychotropics/guidelines/travelregulations/Intl_guidelines_travell_study/12-57111_ENG_Ebook. pdf. 